\title{
Improving irrigation water delivery performance of a large-scale rice irrigation scheme
}

\begin{abstract}
The availability of irrigation water and its equitable allocation in a large-scale rice irrigation scheme of Malaysia have been modeled. The model reliably estimates available water for irrigation at the intake of the main canal and simulates the recommended irrigation deliveries for 120 tertiary canals. Different water allocation and management scenarios were evaluated based on the sensitivity of the growth stages of rice to water, varying field-water demand, and perceived water shortages. The model provides a quantitative assessment not only of water allocation for irrigation but also of day-to-day or periodic irrigation delivery performances for a large-scale rice irrigation system. It provides $86 \%$ adequacy and $87 \%$ equity of irrigation delivery in the main season (August-December). The corresponding performance indicators provided by the model are 74 and $89 \%$ in the off-season (February-June). The dependability of water supply is higher in the off-season than in the main season, while the relative water supply (RWS) is the converse. RWS often becomes $>1.0$ in the main season, while such a RWS is rarely obtained in the off-season. The model augments the water delivery performance of the scheme and hence would serve as a useful tool for irrigation managers in decision making.
\end{abstract}

Keyword: Irrigation deliveries; Modeling; Performance indicators; Rice; Tertiary canals 